\title{
Protective Effect of Pentoxifylline on Growth Plate in Neonatal Rats Following Long-Term Phototherapy
}

\author{
MEHMET EMRE ATABEK, OZGUR PIRGON, AND H. HASAN ESEN \\ Departments of Pediatric Endocrinology [M.E.A., O.P.] and Pathology [H.H.E.], School of Medicine, Selcuk University, \\ 42080 Konya, Turkey
}

\begin{abstract}
We demonstrated previously that receiving long-term phototherapy was associated with early impairment of growth plate structure in neonatal rats, and oxidative stress may be the main risk factor for growth plate injury. The purpose of this study was to examine the histomorphometric effects of pentoxifylline treatment on the growth plate. Sixty weanling Sprague-Dawley rats were randomly separated into three equal groups. Group A, the control group, did not receive phototherapy and pentoxifylline. Groups $\mathrm{B}$ and $\mathrm{C}$ were exposed to phototherapy for $7 \mathrm{~d}$. In addition to phototherapy, group C was also given pentoxifylline during the study period. Compared with zonal lengths on $\mathrm{d} 7$ after initiation of phototherapy, group B had significantly lower values than group A for all zonal lengths $(p<0.001)$. Zonal lengths of growth plate were increased significantly with pentoxifylline treatment in group $\mathrm{C}$ for $7 \mathrm{~d}$ compared with group B $(p<0.001)$. After phototherapy, group B had significantly higher values than groups $\mathrm{A}$ and $\mathrm{C}$ for plasma malondialdehyde levels $(p<0.001)$. The pentoxifylline was found here to have some potential to reduce the effects of phototherapy on growth plate in neonatal rats at a relatively low dose. (Pediatr Res 62: 163-166, 2007)
\end{abstract}

$\mathrm{T}_{1}$ he growth plate is a highly organized cartilage structure located between the epiphyseal and metaphyseal bones at the distal ends of the long bones (1). Longitudinal bone growth is the result of chondrocyte proliferation and subsequent differentiation in the epiphyseal growth plates of the long bones. It is regulated by a multitude of genetic and hormonal factors, growth factors, environment, and nutrition (2-5). Regarding effects of radiation therapy on chondrocytes, Pateder et al. observed no change in transforming growth factor $\beta$ (TGF- $\beta$ ) gene expression (6), whereas Margulies et $a l$. found that TGF- $\beta$ expression decreased and fibroblast growth factor 2 increased after irradiation (7). Moreover, there is evidence that growth plate chondrocytes, osteoclast precursors, and vascular endothelial cells are more sensitive to radiation than osteoblasts $(8-10)$. All these contribute to establishing the final height of an individual.

Phototherapy administered to newborns with jaundice is considered to be a rather benign procedure with few side effects such as rash, loose stools, increased insensible water loss, and dehydration (11). Although phototherapy has been in use for a long time and its effects on the body have been studied extensively, so far, no studies have investigated the

Received January 19, 2007; accepted March 21, 2007.

Correspondence: Mehmet Emre Atabek, M.D., Selcuk University Meram Tip Fakultesi, Cocuk Sagligi ve Hastaliklari, 42080 Konya, Turkey; e-mail: meatabek@hotmail.com relationship between the growth plate and phototherapy. We previously showed the damaging effect of phototherapy by increased oxidative stress on growth plate in newborn rats. Moreover, we showed functional damage and a harmful effect on longitudinal growth of phototherapy on the SpragueDawley rat growth plate (12). Therefore, we hypothesized that pentoxifylline would ameliorate the adverse effects of phototherapy on the growth plate.

\section{METHODS}

Study groups. Sixty weaning Sprague-Dawley rats were randomized into three groups. As all rats in this study were in the first $7 \mathrm{~d}$ of life, all were being breast-fed. Group A, the control group, did not receive any treatment. Phototherapy was administered to 40 animals (groups B and C) for $7 \mathrm{~d}$ by a bank of two white and two blue lights, with wavelengths of 400-500 nm, placed $50 \mathrm{~cm}$ above the rats. In addition, one half of the phototherapy-exposed rats (group C) were administered pentoxifylline [1-(5-oxohexyl) 3,7-dimethyl xanthine] (TRENTAL, Hoechst, Frankfurt, Germany) at the same time. Each of the 20 animals in group $C$ received an intraperitoneal injection of pentoxifylline at a dose of $50 \mathrm{mg} / \mathrm{kg}$ twice daily during the study. This study was performed in the Selcuk University Experimental Research Center with the permission of the Ethics Committee of Selcuk University. Animal rights oversight rules provided by Turkish laws were followed in the study.

Study design. The drug was well tolerated by all the animals. There were no deaths in the observation period. At $7 \mathrm{~d}$ after the initiation of phototherapy, the animals were killed by an intraperitoneal injection of Telazol $30 \mathrm{mg} / \mathrm{kg}$ (Fort Dodge Animal Health, Fort Dodge, IA). The proximal part of the tibia was split sagittally and fixed in $10 \%$ formaldehyde. The $5-\mu \mathrm{m}$ sagittal tibial sections were stained using hematoxylin-eosin. Zonal mean lengths $(\mathrm{mm} \times$ $10^{-2}$ ) of three different areas covered resting, proliferative, and hypertrophic zones of the growth plate cartilage were measured using an Olympus $\mathrm{BH} 2$ (Olympus Optical Co. Ltd., Tokyo, Japan) microscope equipped with a high-resolution video camera. The images were processed by an IBMcompatible personal computer, high-resolution video monitor, and image analysis software (Bs200ProP, BAB Imaging Systems, Ankara, Turkey).

Measurement of growth plate height and zone height. Tibial growth plate heights were determined on hematoxylin-eosin-stained sections. The cartilaginous resting zone was denoted as the region between the secondary center of ossification to the region where chondrocytes align into columns. The proliferative zone comprised the region containing columnar chondrocytes of constant size. The hypertrophic region comprised all enlarged chondrocytes distal to the proliferative zone and proximal to the primary center of ossification. Heights were determined by drawing a vertical line between zones as defined. A minimum of 20 measurements were made along the tibial plateau and the mean vertical height was calculated. Growth plate zone heights were summed up to give total growth plate height representing the distance between the primary and secondary centers of ossification (Fig. 1).

Measurement of malondialdehyde. We, therefore, studied malondialdehyde concentrations, which is a commonly used index of lipid peroxide. Blood samples were centrifuged at $3000 \mathrm{rpm}$ for $3 \mathrm{~min}$ within $15 \mathrm{~min}$ of collection. The supernatant fluid was neutralized with $4 \mathrm{M} \mathrm{NaOH}$. The neutralized supernatant $(1 \mathrm{~mL})$ was reacted with $1 \mathrm{~mL}$ thiobarbituric acid (TBA $0.67 \%$ ), and the mixture was then heated at $100^{\circ} \mathrm{C}$ for $30 \mathrm{~min}$. The absorption of cooled samples was measured at $532 \mathrm{~nm}$. Malondialdehyde concentrations were calculated as $\mu \mathrm{mol} / \mathrm{L}$ (13). 


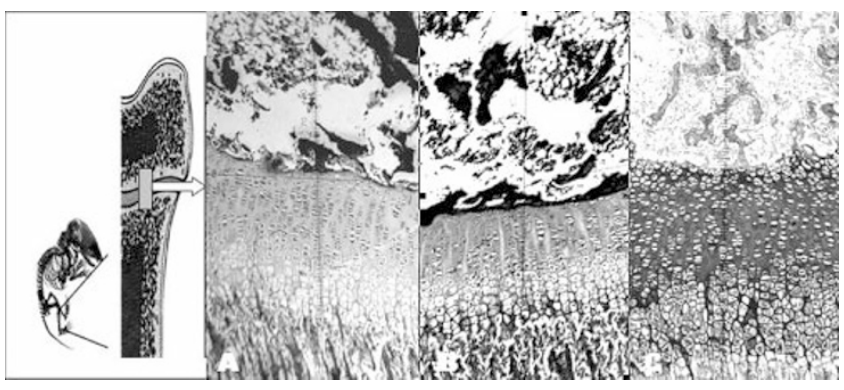

Figure 1. Relationship between anatomic regions of tibia and the growth plate. Histologic section from the growth plate showing well-established zonal lengths and cellularity. Group A, control group; group B, phototherapyexposed group; group $\mathrm{C}$, phototherapy-exposed and simultaneously administered pentoxifylline group (magnification $\times 75$ ).

Statistical analysis. Data were analyzed using the Statistical Package for Social Sciences version 11.0 (SPSS Inc., Chicago, IL). Comparisons between the three groups were done using analysis of variance. Statistical correlations between malondialdehyde and the other variables (zonal lengths) were studied using the Pearson test $(r)$. In addition, multiple linear regression analysis was performed to determine which variables predicted total zonal length in rats receiving phototherapy. We included groups (group $\mathrm{B}=1$ and group $\mathrm{C}=2$ ) and malondialdehyde levels as independent variables in the model. Data are presented as means (SD), and results were accepted as statistically significant at $p<0.05$.

\section{RESULTS}

Compared with zonal lengths on d 7 after phototherapy between the groups, the phototherapy group (group B) had significantly lower values than the controls (group A) for all zonal lengths $(p<0.001)$. Zonal lengths of growth plate were increased significantly by treatment with pentoxifylline (group C) for $7 \mathrm{~d}$, compared with groups A and B $(p<0.001)$ (Table 1; Figs. 1 and 2).

After phototherapy, the phototherapy group (group B) had significantly higher values than the controls (group A) for plasma malondialdehyde levels $(5.8 \pm 0.41$ versus $5.09 \pm$ $0.25 \mu \mathrm{M}, p<0.001)$. The administration of pentoxifylline also resulted in a decrease in malondialdehyde levels in group $\mathrm{C}(4.2 \pm 0.62 \mu \mathrm{M}, p<0.001)$. No correlations were found between malondialdehyde levels and growth plate zonal lengths in group A. Plasma malondialdehyde levels were correlated with

Table 1. Mean (SD) zonal lengths and plasma malondialdehyde results and differences between the three groups (analysis of variance)

\begin{tabular}{|c|c|c|c|c|}
\hline & $\begin{array}{l}\text { Group A } \\
(n=20)\end{array}$ & $\begin{array}{l}\text { Group B } \\
(n=20)\end{array}$ & $\begin{array}{l}\text { Group C } \\
(n=20)\end{array}$ & $p$ \\
\hline $\begin{array}{l}\text { Total zone } \\
\qquad\left(\mathrm{mm} \times 10^{-2}\right)\end{array}$ & $118.48 \pm 4.50$ & $88.15 \pm 6.56$ & $99.11 \pm 4.25$ & $<0.001 *$ \\
\hline Reserve zone & $6.4 \pm 0.85$ & $5.13 \pm 0.36$ & $5.46 \pm 0.55$ & $<0.001^{*}$ \\
\hline $\begin{array}{l}\text { Proliferative } \\
\text { zone }\end{array}$ & $29.25 \pm 1.68$ & $20.6 \pm 3.0$ & $27.73 \pm 1.51$ & $<0.001^{*}$ \\
\hline $\begin{array}{l}\text { Hypertrophic } \\
\text { zone }\end{array}$ & $20.87 \pm 1.12$ & $15.4 \pm 1.44$ & $18.29 \pm 0.95$ & $<0.001 *$ \\
\hline Ossifying zone & $61.57 \pm 3.20$ & $47.08 \pm 4.25$ & $47.62 \pm 2.27$ & $<0.001 *$ \\
\hline $\begin{array}{l}\text { Malondialdehyde } \\
(\mu \mathrm{mol} / \mathrm{L})\end{array}$ & $5.09 \pm 0.25$ & $5.8 \pm 0.41$ & $4.2 \pm 0.62$ & $<0.001^{*}$ \\
\hline
\end{tabular}

Data are expressed as means \pm SD.

Group A, control group; group B, phototherapy-exposed group; group C, phototherapy-exposed and simultaneously administered pentoxifylline group.

* Significance between the three groups (A vs B, A vs C, and B vs C).

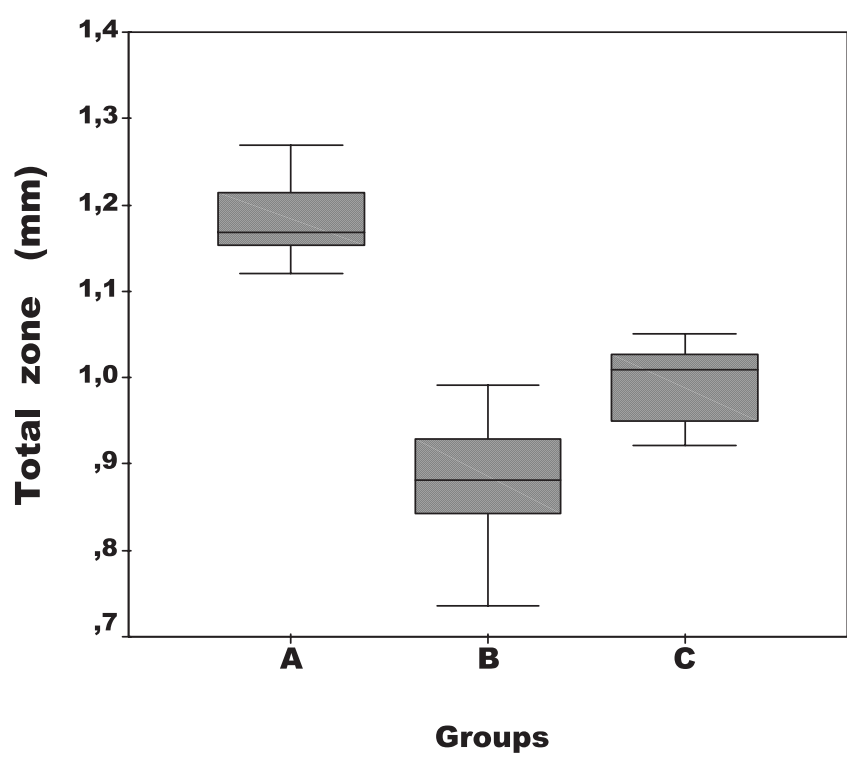

Figure 2. Comparisons between groups for total zone length of growth plate. Group A, control group; group B, phototherapy-exposed group; group C, phototherapy-exposed and simultaneously administered pentoxifylline group. (Groups A and B: $p<0.001$, group B and C: $p<0.001$, groups A and C: $p<0.001)$.

the size of proliferative zone in group B $(r=-0.539, p$ : 0.014). However, there were no correlations between malondialdehyde and the other zonal lengths in group $\mathrm{C}$ (Table 2). In multiple linear regression model for groups $\mathrm{B}$ and $\mathrm{C}$, receiving pentoxifylline treatment was the best predictor of the size of total zonal length $(\beta=0.714, p<0.001)$, with the total variance explained being $51 \%$ (Table 3 ). We included groups (group $\mathrm{B}=1$ and group $\mathrm{C}=2$ ) and malondialdehyde levels as independent variables in the model.

\section{DISCUSSION}

In this study, we again documented experimental evidence of adverse effects on the growth plate of phototherapy as we did in our previous study. Moreover, we demonstrated that pentoxifylline would ameliorate the adverse effects of phototherapy on the growth plate. In a growing bone, growth plate contains proliferating and expanding chondrocytes together with cartilage matrix and is the site of longitudinal growth (14). Various genetic, nutritional, and environmental factors determine and affect linear growth and bone turnover, but in this article, we focused on a damaged growth plate by phototherapy and its protection by pentoxifylline treatment.

In our previous study, we described the damaging effects of phototherapy on an active growth plate in the newborn rats (12). This effect had been illustrated by the dramatic reduction in proliferative activity observed after phototherapy and by the marked loss of zonal lengths had been reached in $1 \mathrm{wk}$. Recent researches have revealed that phototherapy (up to $40 \mathrm{~mW} /$ $\mathrm{cm}^{2} / \mathrm{nm}$ ) is a photodynamic stress and can induce lipid peroxidation $(15,16)$. Du et al. (17) reported that lipid peroxidative stress analyzed by the malonaldehyde assay was significantly elevated in photodynamic-treated cells. Ostrea et al. (18) reported that the exposure of red blood cells to phototherapy light in the presence of a sensitizer (bilirubin) 
Table 2. Pearson correlation between plasma malondialdehyde and the zones in the groups

\begin{tabular}{|c|c|c|c|c|c|c|}
\hline Zone & \multicolumn{2}{|c|}{ Group A } & \multicolumn{2}{|c|}{ Group B } & \multicolumn{2}{|c|}{ Group C } \\
\hline Total & 0.177 & 0.469 & -0.331 & 0.154 & 0.078 & 0.742 \\
\hline Proliferative & 0.036 & 0.885 & -0.539 & $0.014^{*}$ & -0.078 & 0.745 \\
\hline Hypertrophic & 0.260 & 0.283 & 0.006 & 0.980 & -0.018 & 0.941 \\
\hline Ossifying & 0.134 & 0.586 & -0.136 & 0.568 & 0.191 & 0.419 \\
\hline
\end{tabular}

Group A, control group; group B, phototherapy-exposed group; group C, phototherapy-exposed and simultaneously administered pentoxifylline group.

* Correlation is significant at the 0.05 level.

resulted in oxidative injury to the red cell membrane as manifested by a significant increase in the concentration of the products of lipid peroxidation in the membrane and hemolysis. The in vitro bilirubin-sensitized photoreaction damages the erythrocytes mainly at the membrane level. In particular, a dramatic decrease of adenosine triphosphatase activity and an increased susceptibility to lipid peroxidation, expressed as malondialdehyde production, were observed (19). There is increasing evidence that many severe diseases of the neonate are caused by oxidative injury and lipid peroxidation. We therefore studied malondialdehyde concentrations, which is a highly reactive metabolite of free radicalinduced lipid peroxide in newborn rats to determine lipid peroxide concentrations.

In this study, pentoxifylline had been shown to partially protect growth plate from the effect of phototherapy in a skeletally immature rat model. Earlier studies have indicated that pentoxifylline reduces oxygen radical production and protects against tissue damage in vivo by the action of its metabolites $(20,21)$. The effects of pentoxifylline on membranes may explain its effects on cell deformability, inhibition of neutrophils priming by TNF- $\alpha$, diminished adherence and aggregation, reduced superoxide production, and improved locomotor responses (22). The positive influence of pentoxifylline on the microcirculation and peripheral oxygenation led to applications of the drug in experimental radiotherapy to improve oxygenation and in restoring the radiobiological effectiveness of photon irradiation (23-26). In these experiments, pentoxifylline was shown to diminish the incidence and severity of late radiation injury. The mechanisms responsible for this effect are unknown. The increase in this oxidative stress cascade within growth plate zones suggests that this mechanism may be responsible for the molecular changes leading to decrease the cellularity of zones. The zonal lengths were increased by the inhibition of oxidative stress by treating with pentoxifylline. Malondialdehyde levels were thought to be decreased to protect from the detrimental effects of injury.

Table 3. Multivariate regression model for phototherapy-exposed rats

\begin{tabular}{|c|c|c|c|}
\hline & \multicolumn{3}{|c|}{ Total zone } \\
\hline & $\beta$ & $p$ & $R^{2}$ \\
\hline Groups B and C & 0.714 & $<0.001$ & 0.51 \\
\hline Malondialdehyde $(\mu \mathrm{mol} / \mathrm{L})$ & 0.023 & 0.308 & - \\
\hline
\end{tabular}

Group B, nonpentoxifylline-administered group (1); group C, pentoxifylline-administered group (2). MDA, plasma malondialdehyde.
As expected, an interaction and inverse correlation between pentoxifylline and malondialdehyde levels were noted. However, pentoxifylline was partially effective at $\mathrm{d} 7$ with a low dose $(50 \mathrm{mg} / \mathrm{kg}$ twice daily). We concluded that malondialdehyde alteration was a protective response as a result of antioxidant effect of pentoxifylline. Moreover, in the study, it was not clear that there has been a problem clinically with phototherapy causing growth plate injury. Further studies are required to document permanent limb length discrepancies in an animal model.

There are several limitations in our study. The only growth plate functional endpoint measured here is growth plate and zonal height. There is no demonstration in this study that the effects of phototherapy even in this animal model are long lasting because the limb lengths were not measured at the end of the growth period to determine whether the limbs treated with phototherapy were in fact short. Therefore, we do not know whether the change in growth plate height is a transient. There is no analysis of the effects of phototherapy (or malondialdehyde) on any other of the multiple potentially important parameters, such as effects on proliferation (as measured by proliferating cell nuclear antigen or bromodeoxyuridine immunohistochemistry), effects on cellularity (as measured by matrix area fraction, clone formation, and the various immunohistochemical markers of importance to the growth plate.

In conclusion, we demonstrated functional damage to the growth plate and adverse effect on longitudinal growth of phototherapy. Therefore, the usefulness of phototherapy in healthy, full-term infants is currently being questioned. Although very commonly used in clinical practice, there still seems to be a lot to study and learn about the effects of phototherapy on humans. Using an in vivo newborn rat model, this study described the effects of phototherapy (light exposure) on the length of growth cartilage layers. As a result, we found significant decreases in zonal lengths of cartilage layers in the rats at $7 \mathrm{~d}$ after initiation of phototherapy, probably through increased oxidative stress. In addition, this lightinduced attenuation of endochondral ossification was redeemed by the systemic administration of an antioxidant, suggesting the effectiveness of such an antioxidant for the prevention of the observed adverse effects of phototherapy.

\section{REFERENCES}

1. Hunziker EB 1994 Mechanism of longitudinal bone growth and its regulation by growth plate chondrocytes. Microsc Res Tech 28:505-519

2. Cancedda R, Descalzi Cancedda F, Castagnola P 1995 Chondrocyte differentiation. Int Rev Cytol 159:265-358 
3. Hering TM 1999 Regulation of chondrocyte gene expression. Front Biosci 4:D743D761

4. Stevens DA, Williams GR 1999 Hormone regulation of chondrocyte differentiation and endochondral bone formation. Mol Cell Endocrinol 151:195-204

5. Robson H, Siebler T, Shalet SM, Williams GR 2002 Interactions between GH, IGF-I, glucocorticoids, and thyroid hormones during skeletal growth. Pediatr Res 52:137-147

6. Pateder DB, Eliseev RA, O'Keefe RJ, Schwarz EM, Okunieff P, Constine LS, Puzas JE, Rosier RN 2001 The role of autocrine growth factors in radiation damage to the epiphyseal growth plate. Radiat Res 155:847-857

7. Margulies BS, Horton JA, Wang Y, Damron TA, Allen MJ 2006 Effects of radiation therapy on chondrocytes in vitro. Calcif Tissue Int 78:302-313

8. Gal TJ, Munoz-Antonia T, Muro-Cacho CA, Klotch DW 2000 Radiation effects on osteoblasts in vitro: a potential role in osteoradionecrosis. Arch Otolaryngol Head Neck Surg 126:1124-1128

9. Krishnan EC, Krishnan L, Jewell B, Bhatia P, Jewell WR 1987 Dose-dependent radiation effect on microvasculature and repair. J Natl Cancer Inst 79:1321-1325

10. Scheven BA, Burger EH, Kawilarang-de Haas EW, Wassenaar AM, Nijweide PJ 1985 Effects of ionizing irradiation on formation and resorbing activity of osteoclasts in vitro. Lab Invest 53:72-79

11. Stoll JB, Kliegman RM 1996 Digestive system disorders. In: Behrman RE, Kliegman RM, Jenson HB (eds) Nelson Textbook of Pediatrics. Saunders, Philadelphia, pp 597-598

12. Atabek ME, Pirgon O, Kurtoglu S, Tavli L, Esen HH, Koylu O, Erkul I 2006 Effects of phototherapy on the growth plate in newborn rats. J Pediatr Orthop 26:144-147

13. Wade CR, van Rij AM 1988 Plasma thiobarbituric acid reactivity: reaction conditions and the role of iron, antioxidants and lipid peroxy radicals on the quantitation of plasma lipid peroxides. Life Sci 43:1085-1093

14. Stevens DA, Williams GR 1999 Hormone regulation of chondrocyte differentiation and endochondral bone formation. Mol Cell Endocrinol 151:195-204

15. Gathwala G, Sharma S 2000 Oxidative stress, phototherapy and the neonate. Indian J Pediatr 67:805-808
16. Gathwala G, Sharma S 2002 Phototherapy induces oxidative stress in premature neonates. Indian J Gastroenterol 21:153-154

17. Du HY, Olivo M, Tan BK, Bay BH 2003 Hypericin-mediated photodynamic therapy induces lipid peroxidation and necrosis in nasopharyngeal cancer. Int $\mathrm{J}$ Oncol 23:1401-1405

18. Ostrea EM Jr, Cepeda EE, Fleury CA, Balun JE 1985 Red cell membrane lipid peroxidation and hemolysis secondary to phototherapy. Acta Paediatr Scand 74:378381

19. Tozzi E, Tozzi-Ciancarelli MG, Di Giulio A, D’Alfonso A, Farello G, Spennati GF, de Matteis F 1989 In vitro and in vivo effects of erythrocyte phototherapy on newborns. Biol Neonate 56:204-209

20. Crouch SP, Fletcher J 1992 Effect of ingested pentoxifylline on neutrophil superoxide anion production. Infect Immun 60:4504-4509

21. Damron TA, Spadaro JA, Horton JA, Margulies BS, Strauss JA, Farnum CE 2004 Novel radioprotectant drugs for sparing radiation-induced damage to the physis. Int J Radiat Biol 80:217-228

22. Maderazo EG, Breaux S, Woronick CL, Krause PJ 1990 Efficacy, toxicity, and pharmacokinetics of pentoxifylline and its analogs in experimental Staphylococcus aureus infections. Antimicrob Agents Chemother 34:1100-1106

23. Collingridge DR, Rockwell S 2000 Pentoxifylline improves the oxygenation and radiation response of BA1112 rat rhabdomyosarcomas and EMT6 mouse mammary carcinomas. Int J Cancer 90:256-264

24. Lee I, Boucher Y, Demhartner TJ, Jain RK 1994 Changes in tumour blood flow oxygenation and interstitial fluid pressure induced by pentoxifylline. $\mathrm{Br} \mathrm{J}$ Cancer 69:492-496

25. Song CW, Hasegawa T, Kwon HC, Lyons JC, Levitt SH 1992 Increase in tumour oxygenation and radiosensitivity caused by pentoxifylline. Radiat Res 130:205210

26. Dion MW, Hussey DH, Doornbos JF 1990 Preliminary results of a pilot study of pentoxifylline in the treatment of late radiation soft tissue necrosis. Int $\mathrm{J}$ Radiat Oncol Biol Phys 19:401-407 